\title{
Implementation of the Air Quality Plan guidelines for the Malopolska Region based on the example of the health resort Rabka Zdrój
}

\author{
Aleksandra Szulc ${ }^{1, *}$, and Barbara Tomaszewska ${ }^{1}$ \\ ${ }^{1}$ AGH University of Science and Technology, Faculty of Geology, Geophysics and Environmental \\ Protection, al. Mickiewicza 30, 30-059 Kraków, Poland
}

\begin{abstract}
It is commonly known that Poland has for many years a lot of problems with air quality. However, Polish legal regulation provides the solutions to improve air quality. One of them is the most important local strategy documents - Air Quality Plan for Malopolska Region (MAQP). This programme assumes taking corrective actions in order to improve air quality in the Malopolska Region. The main objective of the work is analysis how the local government Rabka Zdrój implement the assumption of MAQP on the municipality area. In order to understand for the implementation of the procedures set in MAQP, a study of the energy structure was presented. The results of analysis shown that the main usage of heating systems, based on solid fuel boilers, is the cause of the low air quality. The final report on the implementation of MAQP in 2013-2015 made it clear, that local governments did not get involved enough in putting in place air quality activities. On the other hand, since 2016, the municipality of Rabka Zdrój has been taking more and more steps to engage in different actions to achieves emission reduction.
\end{abstract}

\section{Introduction}

For many years Poland has struggled with the problem of poor air quality. Every year, especially in the autumn and winter period, the permissible concentration levels of pollutants are excessive [1-3]. Air quality has become increasingly weaker which makes it necessary to take appropriate measures to protect human health and improve its quality of life. In that regard, it is necessary to determine the corrective long and short-term actions. The local government should provide full monitoring of pollutants and define the main reason which cause poor air quality. Institutions which are responsible on environmental monitoring in Poland is the Chief Inspectorate for Environmental Protection (CIEP). The CIEP Inspectorate is responsible for the assessment of air quality standards in the country, as well as supervision and coordination of Voivodeship Inspectorates for Environmental Protection (VIEP) activities. In accordance with the Act of 27 April 2001, Environmental Protection Law, VIEP are obligated to air pollution monitoring system [4]. Data provided by State Environmental Monitoring allows to prepare annual air quality report for

\footnotetext{
* Corresponding author: aszulc@agh.edu.pl
} 
voivodeship. In turn, the identification of areas with exceeding the permissible level of pollutant concentration obliges the regional authorities to drafting an Air Quality Plan (AQP). The developed AQP is presented and consulted with local governments. The overarching objective of this document is to determine activities which implementation will allow to reach permissible level of air pollutions in assumed time interval. The local governments are obligated to realisation the activities related to the achievement of the goals set in AQP.

The aim of this work is to shown how the implementation of the different tasks evolves progress on realization of assumption on AQP in Malopolska Region. The analysis was based on review of the reference literature and access elaborations, related with realisation widespread targets in Air Quality Plan for Malopolska Region (MAQP). The research include description of health resort Rabka Zdrój with a particular focus on energy structure and measures taken towards reduction of air pollution by local government.

\section{Description of the research area}

\subsection{Air Quality Plan for the Malopolska Region}

The MAQP is one of the most important strategy programmes concerning the air quality. It had been prepared on the basis of the regulation of the Minister of Environment of 11 September 2012 - On air protection programs and short-term action plans [5]. In relation to The Environmental Protection Law, adopted AQP should be updated every three years if the standards of air quality are still excessive. In MAQP demarcated three areas (zones) where an assessment of air quality is made: The Kraków Agglomeration, the city of Tarnów, Malopolska area. The most important objective of the programme is to achieve acceptable levels of air pollutants in Malopolska Region up to 2023. Moreover, MAQP identify the direction of actions which should be taken by local government to reduce emission of air pollution. Such action are: replacement of old, inefficient solid fuels boilers, thermal modernisation of the buildings, exploitation of renewable energy resources, extension and modernisation of heating networks and gas networks, reduction of transport emission, reduction of industrial emissions, environmental education and others [6]. The MAQP was updated in 2017 and contains an analysis of the current state, which was made on the basis of air quality monitoring conducted in the province Malopolska Region. Based on air quality analysis, designated the vulnerable zones and defined the impact of air pollution on the residents health. With regard to the defined causes of high concentrations of pollutants, detailed corrective actions are presented. Corrective action have been divide into short-term and long-term periods. Short-term activities are implemented when the concentration of pollutants in the air reaches the alarm level. In the other hand, long-term activities are aim to sustainable and permanently way to reduce air pollution. Summary of the MAQP is presented in the expected results within individual zones of the Malopolska Region [7]. The programme which ensures adequate support to MQPA is LIFE IP "Implementation of Air Quality Plan for Malopolska Region - Malopolska in a healthy atmosphere" LIFE-IP MALOPOLSKA/LIFE14 IPE/PL/021. The LIFE programme shall supports 62 partners - including the Rabka Zdrój municipality [8]. 


\subsection{Health resort Rabka Zdrój}

Rabka Zdrój is one of the most popular and visited health resorts in Poland, located in the province of Malopolska (Fig. 1) [9]. It is worth mentioning, that the basic requirement for receiving health resort status is having a climate with medicinal properties and natural resources of therapeutic water [10]. One of the factors which is taken into consideration in assessing the therapeutic properties of climate is quality of air in the health resort area. Rabka Zdrój as well as other health resorts in Malopolska are faced with significant exceedance limit values with regard to concentrations of pollutants in the air. For the most part, this phenomenon is caused by combustion of solid fuels which are poor quality and use for this inefficient households furnaces [11]. In addition, the location of Rabka in Rabczańska Valley causes a lack of ventilation of the health resort area, which often results with the occurrence of "smog".

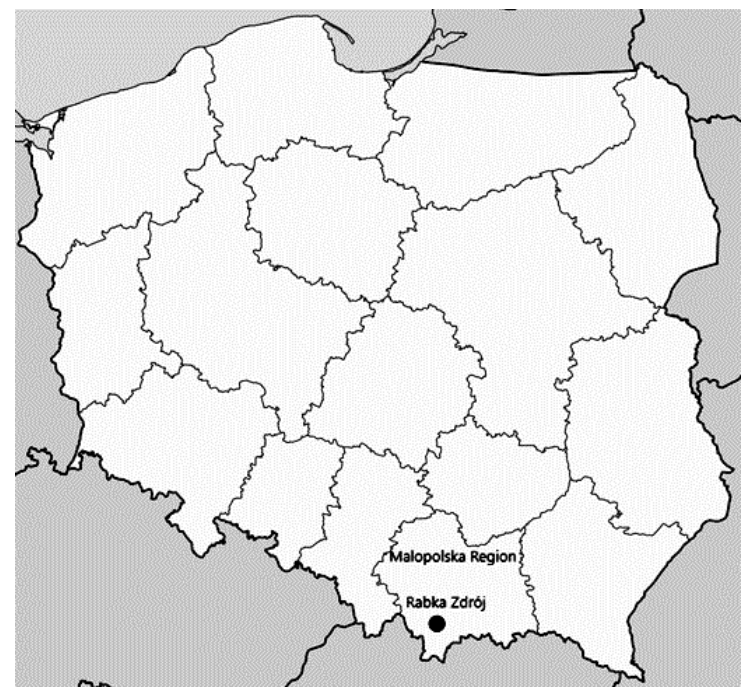

Fig. 1. Administrative localisation the municipality of Rabka Zdrój.

Rabka Zdrój is obliged to introduce the rules adopted in MAQP, which apply in the area of the whole voivodeship. Rabka Zdrój has been covered by continuous emission measurement in 2014 and 2017. The analysis of the data showed that the average annual concentrations of particular matter $\mathrm{PM}_{10}$ and benzo(a)pyrene were in 2014: $34 \mu \mathrm{g} \cdot \mathrm{m}^{-3}$ and $8 \mathrm{\eta g} \cdot \mathrm{m}^{-3}$; in 2017: $35 \mu \mathrm{g} \cdot \mathrm{m}^{-3}$ and $7.5 \mathrm{\eta g} \cdot \mathrm{m}^{-3}$ [12]. The permissible level of annual concentration of $\mathrm{PM}_{10}$ was not exceeded. Unfortunately, annual concentration of benzo(a)pyrene has been exceeded eightfold. The permissible number of days in a year with exceeding the permissible daily concentration of $\mathrm{PM}_{10}$ is 35 days [13]. On the area of health resort the number of days with exceeded was 22 days in 2014, while in 2017 it was 66. This results show that Rabka Zdrój have problems with air quality. In accordance with report about the implementation of the MAQP in 2013-2015, the municipality of Rabka Zdrój has been achieved $0.066 \mathrm{Mg} \cdot \mathrm{a}^{-1}$ of $\mathrm{PM}_{10}$ emission reduction. While government of Malopolska set a target value of $\mathrm{PM}_{10}$ emission reduction for Rabka Zdrój in 2015 as a $9.25 \mathrm{Mg} \cdot \mathrm{a}^{-1}$. Moreover, the emission level of $\mathrm{PM}_{10}$ was $97.8 \mathrm{Mg} \cdot \mathrm{a}^{-1}$ in 2015 but in connection with objective noted in MAQP in 2023 should be $8.12 \mathrm{Mg} \cdot \mathrm{a}^{-1}$ [14]. It can be expected that this target will be very difficult to achieve up to 2023 . 


\section{Analysis of the current state in Rabka Zdrój}

\subsection{Identification of energy structure}

In order to update of MAQP an inventory of emission sources was carried out in the city area of Rabka Zdrój. The analysis was done for 2015 which was adopted as the base year for the updates MAQP of 2013. The inventory was based on method of direct interview. It consist of surveys to be completed by local society. The analysis of data was based on assumption general model for measurement by counting proposed by Bich and Pennecchi [15]. In the city of Rabka Zdrój, inventory was carried out in 699 buildings which account less than $25 \%$ of all buildings intended for surveys [4]. Performed analysis of the data (Fig. 2) indicate that the most common types of heating system in Rabka Zdrój is gas heating $-46.8 \%$ of all. The second one used system is solid fuel heating $45.8 \%$, which has a significant contribution to poor air quality in the health resort area. It should be emphasised that the questionnaire was conducted in the city area. However, it is clear for other sources that within the rural areas of the municipality of Rabka Zdrój do not have access to gas networks [16]. Therefore, it is to be expected that the popularity of using solid fuel boilers would be increasing in the rural area.

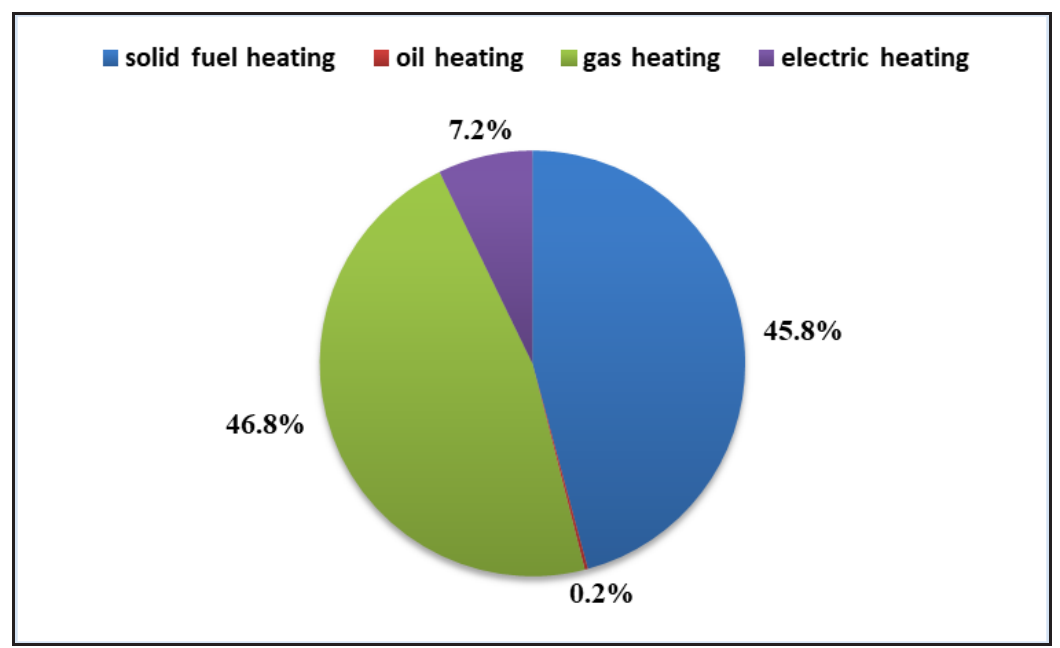

Fig. 2. Types of heating systems in city area of Rabka Zdrój in 2015.

A significant effects on the emission of pollutants is also the usage of central heating boilers. Highly efficient boilers emit far fewer pollutants than low-efficiency boilers. In addition, solid fuel boilers they may divide into: automatic and manual. It depend from types of fuel feeding. Automatic fuel boilers have higher efficiency and emit far fewer pollutants than manual boilers. The analysis of boilers technical condition in Rabka Zdrój, show that the largest group are manual boilers for solid fuel (Fig. 3). Number of manual boilers is 6 times higher than more environmental friendly automatic boilers. From comparison the age of manual heating boilers results that more than $38 \%$ - precisely 114 boilers, exceeds 10 years. The second most common group of manual boilers have less than 5 years $(30 \%)$. The figures reveal that new automatic boilers (under the age of 5) only represents $10 \%$ of all using boilers (Fig. 3). 


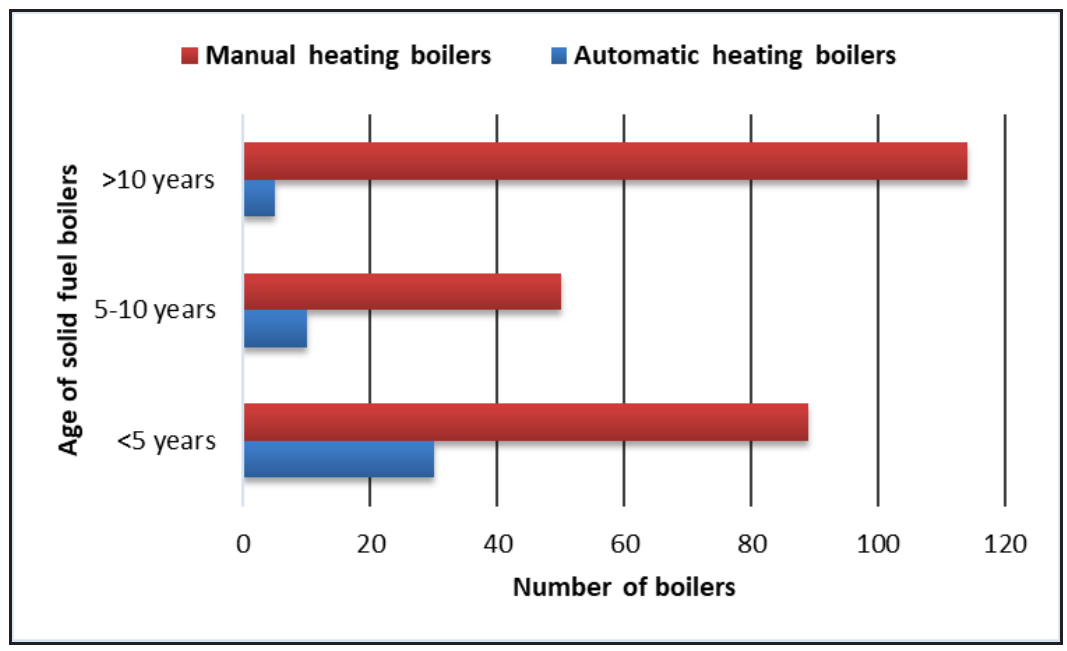

Fig. 3. Age of solid fuel boilers in city area of Rabka Zdrój in 2015.

The inventory of energy sources and air pollutant emission was also drafted under the Low Carbon Economy Plan (LCEP) for Rabka Zdrój. As a base year adopted the 2014. Into consideration was taken: 349 private houses, 56 multi-family houses and 20 public buildings. The results of surveys was used for the preliminary assessment of energy structure in the area of Rabka Zdrój. The most common used types of heating system is solid fuel heating as much as $75 \%$ in private houses (Fig. 4). Another popular source of heat is gas heating. In multi-family housing the main source of energy are central heating boilers for solid fuel (52\%). The second commonly used heating system is electric heating. In case of public buildings there occurs completely different energy structure. Of the 20 analysed buildings, only three of them used solid fuel, while the rest was using gas heating [16].

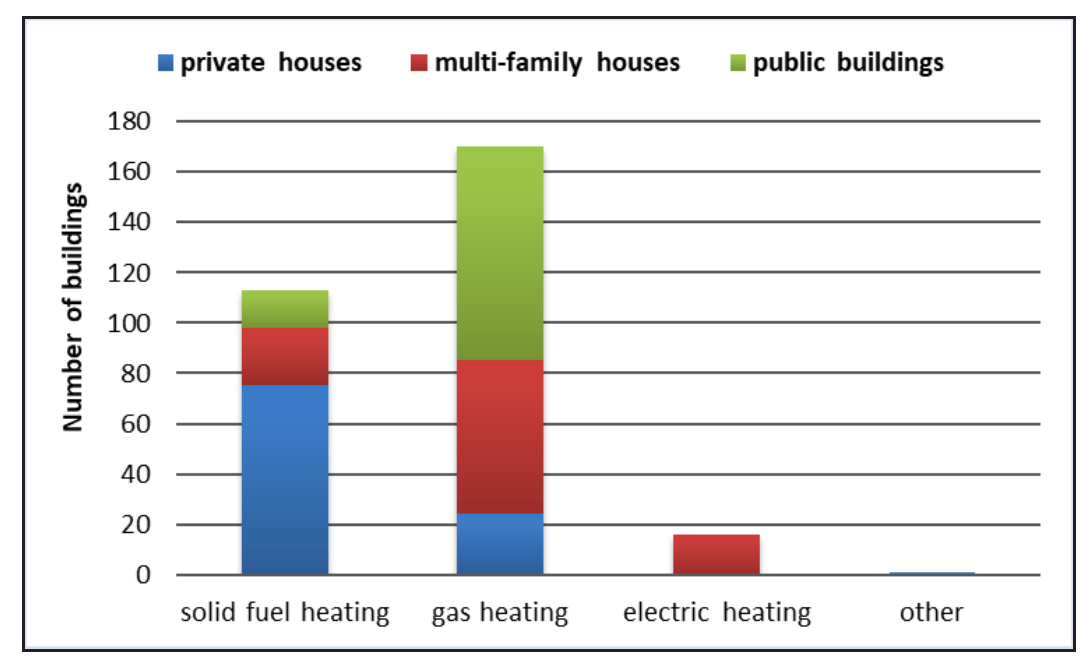

Fig. 4. Types of heating system in municipality of Rabka Zdrój in 2014.

It should be noted that most of used solid fuel boilers have been in operation for over 10 years. Low Carbon Economy Plan 2017 containing information that by 2020 will be exchange 870 solid fuel installations old type, which are $30 \%$ of all existing installation. On the basis of simple calculations, it is easy to show that the total number of old type boilers 
is approximately 2900. The old heating installation based on solid fuel boilers will be replacement by gas boilers, highly efficient and low emission solid fuel boilers and installation of renewable energy.

\subsection{Actions taken by the local government for air protection}

In connection with final report on the implementation of MAQP in 2013-2015, had been taken following tasks to reduce air pollution emission on the municipality Rabka Zdrój area:

1) one low-efficiency solid fuel boiler has been replaced for gas boiler,

2) measure have been taken to the thermo-modernisation of public buildings,

3) maintaining road cleanliness in order to prevent secondary pollutant emission,

4) the implementation of integrated policies at local level with an emphasis on the air quality.

Costs incurred in 2013-2015 for implementation tasks aimed at improve air quality was not exceed 250000 PLN $(\sim 57500 €)$.

In 2016, was carried out 323 control of the waste incineration on the area of municipality. Irregularities and non-compliance legislation have been demonstrated in 16 cases. Local government also sign the agreement with VIEP for taking the measurement of particular matter $\mathrm{PM}_{10}$ and benzo(a)pyrene a year-round 2017. In addition, in the first half of 2017 has been taken comparative measurement of $\mathrm{PM}_{10}$ sensors. The main aim of measurement was compared the results between widely available low-cost measurement and measurement using the reference method. The comparative action was carried out from February to June 2017. Currently, in Rabka Zdrój was mounted four low-cost measurement. Data acquired from sensors are published on the municipality website and used for information and education purposes [17]. City Council in January 2017 adopted Resolution of the Low Carbon Economy Plan for Rabka Zdrój. Primary objective of the Plan is to improve air quality on the area of health resort and protection of human health. Furthermore, municipality employs Ekomenager whom is responsible for widespread environmental education local community. Ekomenager is also support for local government in implementation of MAQP objectives. The municipality Rabka Zdrój joined to "The Sądecki Experiment 2". The main objective of the Experiment is elaboration and implementation of distribution system "Blue coal". Since 2016, Rabka Zdrój is also partners in Cluster of Energy Green Podhale, whose activity should make an important contribution to: improvement environmental conditions, energy security and strengthening the local economy [10]. Rabka Zdrój also acceded to the cooperation with project Ecopartners for Solar Energy for Malopolska. Project have been submitted up to competition Regional Operational Programme for Malopolskie Voivodeship on years 2014-2020. Obtaining finance on the project will help with development of technologies for the production of energy from renewable sources in Rabka Zdrój and twin municipality.

At the beginning of 2018, the municipality have started project funded under Regional Operational Programme for Malopolskie Voivodeship on years 2014-2020. Rabka Zdrój has achieved funds amounting to:

- 1538847.19 PLN ( $354000 €$ ) to exchange 171 old and inefficient combustion installations solid fuels for installations that meets requirements eco-design, that also be powered by solid fuel.

- 1399999.53 PLN ( $322060 €$ ) to exchange 100 combustion installations solid fuels for gas installations. 


\section{Summary}

The Air Quality Plan for the Malopolska Region is one of the most important programme conducted in the area of the voivodeship. According to the stated corrective actions of the plan the air quality in the Malopolska Region would significantly improve. The main objective of the program is to achieve acceptable levels of air pollutants up to 2023. Unfortunately, the problem with poor air quality also relates to the health resort area. Therefore, it is very important to take an action to improve the air quality by local governments. The analysis of energy structures shows, that the most common used heating system in private houses is solid fuel heating. It is estimated that in the area of the municipality was installed almost 3000 solid fuel boilers in 2014. The public buildings are more environmental friendly because main source of energy is connection with gas network. The most popular are manual heating boilers which have more than 10 years of operation. Using low-efficient boilers for solid fuel, contribute significantly to the growth air pollution in health resort area. Due to the fact that Rabka Zdrój has the status of a health resort it should concentrate all its attention to take care of climatic values. In 2013-2015 municipality focused on thermos-modernisation of public buildings. Consequently, the rest of activities has virtually been disregarded. As a result, municipality achieved less than $0.2 \%$ level of emission reduction determined in MAQP. However, local government activities in air pollution field constantly increase since 2016. Rabka Zdrój acceded to few project - for example The Cluster of Energy Green Podhale, which has as its most important aim to improve air quality. Form Regional Operational Programme for Malopolskie Voivodeship on years 2014-2020, had been allocated funding for replacement old solid fuel boilers with new, more efficient and less polluting. Moreover, Rabka Zdrój as a partner in project Eco-partners for Solar Energy for Malopolska - awaiting for assessment of the application. It should be noted that local governments have taken some action to improve air quality in the health resort area, but the effects of their implementation are not visible yet.

The scientific work was financed from budgetary sources for years 2017-2021, as a research project under the "Diamentowy Grant" programme (grant agreement No. DI2016 003946). Part of the work was prepared under the AGH-UST statutory research grant No. 11.11.140.031.

\section{References}

1. M. Zawada, M. Starostka-Patyk, Transportation Research Procedia 16, 587-597 (2016)

2. WHO, World Health Organization World health statistics 2017: monitoring health for the SDGs, Sustainable Development Goals (2017)

3. K. Rawicki, M. Czarnecka, J. Nidzgorska-Lencewicz, Web of Conferences 28, 01025 (2018)

4. The Act of 27 April 2001 Environmental Protection Law (Journal of Law of 2001 No. 62 item 627)

5. Regulation of the Minister of Environment of 11 September 2012. On air quality plan and short-term action plans (Journal of Law of 2012 item 1028)

6. A. Lochno, B. Wawrzynowska, M. Placek, A. Bechta, A. Bartocha, M. Załupka, M. Janowska, I. Sobecki, T. Przybyła, W. Wahling, W. Łata, T. Kasjan, R. Grzebiela, 
Attachment No. 1 to resolution No. XXXII/451/17 Lesser Poland Regional Assembly of 23 January 2017

7. A. Lochno, B. Wawrzynowska, M. Placek, A. Bechta, A. Bartocha, M. Załupka, M. Janowska, T. Przybyła, I. Sobecki, W. Wahling, W. Łata, T. Kasjan, Attachment No. 2 to resolution No. XXXII/45ńn/ń7 Lesser Poland Regional Assembly of z 23 January 2017

8. Website of LIFE Programme - Malopolska in healthy atmosphere, https://powietrze.malopolska.pl/en/life-ip/life-ta-project/ (accessed 22.01.2017)

9. A. Omulecki, A. Nowak, A. Zalewska, Clinics in Dermatology 14, 679-683 (1996)

10. The Act of 28 July 2005 on Health Resort Medical Care, Health Resorts, Health Resort Protection Areas and Health Resort Commune. (Journal of Law of 2005 No. 167 item 1399)

11. W. Wójcikowski, Technical Transactions, 221-229 (2007)

12. Website of Voivodeship Inspectorates for Environmental Protection in Kraków: http://monitoring.krakow.pios.gov.pl/danepomiarowe/manualne (accessed 17.01.2017)

13. Regulation of the Minister of Environment of 24 August 2012. On the levels of certain substances in the air (Journal of Law of 2012 item 1031)

14. A. Lochno, M. Wawrzynowska, P. Trzaska, A. Bechta, I. Sobecki, Report on the implementation of the Air Quality Plan for Malopolska Region in 2013-2015. Marshal's Office of the Malopolska Region, Krakow (2016)

15. W. Bich, F. Pennecchi, Metrologia 49, 1, 15-19 (2012)

16. G. Godziek, A. Sokulska, Low Carbon Economy Plan for Rabka Zdrój. Attachment No. 2 to resolution No. XXVIII/212/17 City Council of Rabka Zdrój of 25 January 2017

17. Website of Rabka Zdrój municipality: http://www.gmina.rabka.pl/main/czyste_powietr ze (accessed 18.01.2017)

18. Cluster of Energy Green Podhale, http://www.zielonepodhale.agh.edu.pl (accessed 19.01.2018) 